\title{
EL NUEVO PROTECCIONISMO. MEDIDAS DE EFECTO EQUIVALENTE Y BARRERAS TÉCNICAS EN LA COMUNIDAD EUROPEA
}

\author{
GERMÁN VALENCIA MARTÍN
}

El objetivo primordial de la Comunidad Europea desde su fundación ha sido la creación de un mercado único sin fronteras interiores entre los Estados miembros, donde la libre circulación de personas, mercancías, servicios y capitales esté plenamente garantizada, por utilizar las palabras del nuevo art. $8 \mathrm{~A}$ del Tratado de la CEE, introducido por el Acta Unica Europea. Sin embargo, pese a los esfuerzos desplegados por las instituciones comunitarias, y a los evidentes logros alcanzados, los Estados no han dejado en ningún momento de idear fórmulas originales para proteger sus mercados internos frente a la competencia. Así, las reglamentaciones de etiquetado, envasado y composición de bebidas y alimentos o los trámites administrativos de homologación de productos industriales, destinados en principio a salvaguardar la salud, la seguridad y los intereses económicos del consumidor o a proteger el medio ambiente, se han utilizado hábilmente como artilugios para dificultar la importación y venta de productos competidores de otros países comunitarios. También los impuestos, redactados en ocasiones en términos sutilmente proteccionistas, o las ayudas públicas, concedidas a empresas, públicas o privadas, incapaces de subsistir en un ambiente competitivo, y un largo etcétera.

En la tesis trato de sistematizar todo este conjunto de nuevas formas de proteccionismo económico, y analizo su compatibilidad / incompatibilidad con las normas del Derecho Comunitario, y, en particular, con la prohibición de las medidas de efecto equivalente a las restricciones cuantitativas a la importación del art. $30 \mathrm{del}$ Tratado de Roma. En esta tarea manejo primordialmente la abundante jurisprudencia del Tribunal de Justicia de la Comunidad, que a lo largo de estos años ha ido delimitando la noción de medidas de efecto equivalente y construyendo el alcance de la prohibición.

Una de las principales conclusiones del trabajo es la constatación de la dificultad de llegar a resultados generales, pues para determinar la legitimidad o ilegitimidad de las medidas, en el supuesto más frecuente de que no sean abiertamente discriminatorias, no queda otro remedio que hacer un análisis del caso concreto, ponderando, con arreglo al principio de proporcionalidad, sus efectos restrictivos sobre el comercio con la importancia de sus objetivos.

Otra de las conclusiones es la constatación de la importante dosis de retórica que 
a menudo acompaña a las declaraciones sobre el mercado único. Este se nos quiere presentar a veces como un espacio a resguardo de cualquier clase de barreras comerciales, cuando la realidad dista de ser esa. Los obstáculos comerciales, aunque en menor medida que en otros momentos, van a acompañar inexorablemente al mercado interior. En primer lugar, porque son consustanciales a toda estructura de poder descentralizada, como es la Comunidad Europea (y ahí está el ejemplo norteamericano); $y$, en segundo lugar, porque en cualquier coyuntura de crisis económica vuelven a aparecer las tentaciones proteccionistas.

He puesto especial interés en el trabajo en analizar casos concretos, $y$, en particular, los que afectan a España y están de mayor actualidad, como, por ejemplo: la obligatoriedad de la letra «ÑN en los ordenadores, que el Estado español defiende por razones de protección del idioma, aunque objetivamente supone una barrera comercial; el contencioso de los turroneros alicantinos con ciertos fabricantes franceses por la utilización de las denominaciones «Jijona» $\mathrm{y}$ «Alicante»; las ayudas del Estado español a la siderurgia o a la minería, contestadas por la Comisión europea por distorsionar la libre competencia, etc.

Finalmente, también estudio la armonizaciónm comunitaria de legislaciones como método fructífero de eliminación de barreras comerciales; y hago una referencia comparativa a los problemas comerciales en el seno del GATT (Acuerdo General sobre Aranceles y Comercio) y de algunos Estados de estructura federal o descentralizada, como los EE.UU. o la propia España. 